\title{
Antioxidant and scolicidal activities of four Iranian Mentha species (Lamiaceae) in relation to phenolic elements
}

\author{
Mojtaba Ranjbar ${ }^{1^{*}},{\text { Mahmoud } \text { Kiani }^{2}}^{(\mathbb{D}}$, Ali Nikpey $^{3}$ \\ ${ }^{1}$ Faculty of Biotechnology, Amol University of Special Modern Technologies, Amol, Iran \\ ${ }^{2}$ Faculty of Medicinal Plants, Amol University of Special Modern Technologies, Amol, Iran \\ ${ }^{3}$ Faculty of Veterinary Medicine, Amol University of Special Modern Technologies, Amol, Iran
}

\section{A R T I C L E I N F O}

Article Type:

Original Article

\section{Article History:}

Received: 11 June 2019

Accepted: 5 October 2019

\section{Keywords:}

Antioxidant

Flavonoid

Mentha

Phenolic compounds

Scolicidal effect

\begin{abstract}
A B S T R A C T
Introduction: There is a growing interest of industry to replace synthetic chemicals by natural products with bioactive properties from plant origin. The present study reported the antioxidant activity and scolicidal effects of the crude extracts from Mentha spicata, $M$. aquatica, M. longifolia, and M. $\times$ piperita var. citrata growing in Iran.

Methods: Total phenolic, flavonoid and flavonol contents of the four Mentha taxa were examined. Two antioxidant assays i.e. free radical scavenging activity (DPPH assay) and reducing power assay were used for determining the antioxidant capacity of the alcoholic extracts. Scolicidal activity of serial dilutions $(15-200 \mathrm{mg} / \mathrm{mL})$ of Mentha extracts was evaluated after 1, 5, 10, 20 and 30 minutes of exposure time.

Results: Methanol was the solvent yielding the highest values of total phenolic (TPC), flavonoid (TFC) and flavonol contents (TFvC). On the other hand, the extracts from $M . \times$ piperita var. citrata gave the highest total phenolic content (191.6 mg gallic acid equivalent per g; GAE/g), total flavonoid content (57.0 mg quercetin per g; QE/g) and total flavonol content (15.3 $\mathrm{mg}$ $\mathrm{QE} / \mathrm{g}$ ) values. The methanol extracts of $M . \times$ piperita var. citrata also gave the strongest DPPH radical scavenging activity (83.2\%), whereas the reducing power yielded absorbance values between 0.189 in M. spicata and 1.16 in M. × piperita var. citrata. The highest scolicidal activity (99.54\%) was observed in $200 \mathrm{mg} / \mathrm{mL}$ methanol extract of $M$. aquatica after 30 minutes of application.

Conclusion: Overall, M. $\times$ piperita var. citrata and M. aquatica could be the taxa of choice for future supplementary studies.
\end{abstract}

Implication for health policy/practice/research/medical education:

Extracts of Mentha species exhibited potent antioxidant and scolicidal activities, which may have significant implications for the future development of anti-parasitic drugs derived from Mentha species.

Please cite this paper as: Ranjbar M, Kiani M, Nikpey A. Antioxidant and scolicidal activities of four Iranian Mentha species (Lamiaceae) in relation to phenolic elements. J Herbmed Pharmacol. 2020;9(3):200-208. doi: 10.34172/jhp.2020.26.

\section{Introduction}

Oxidation is known to have negative effects, especially in industrial context. Oxidation reactions occur in foods and cosmetics, often because of the prolonged exposure to oxygen. Food preservation represents an issue of concern and requires assurance of protection from microbial spoilage and prolongation of shelf life (1). The damaging effects caused by oxidation have commonly been reduced by the usage of synthetic antioxidants. However, health critics and researchers are questioning the safety of such compounds, as the usage of synthetic chemicals has increasingly become viewed as a threat to human health. Plant-derived compounds have gained considerable importance due to their increasing applications as additives in food and cosmetics technologies for the protection of easy oxidizing components (2). On the other hand, such compounds are of interest for the pharmaceutical industries to combat human diseases of, for example, microbial and parasitical origins. Phytochemicals may serve as key compounds to develop new drugs to be used against many chronic diseases recognized as complicated to handle. Hydatidosis caused by the larval stage of 
Echinococcus spp. is a major zoonotic infection that is detrimental to both humans and animal husbandries in many countries (3). Nowadays, parasitic diseases are usually dealt with synthetic drugs. However, such cures have some disadvantages, e.g. side effects, cost and risk of misuse leading to drug resistance, unavailability of treatments in developing countries, and environmental and food pollution (4). These problems stimulated the research of other potential therapeutic options, plantsbased derivatives in particular. Accordingly, a large number of medicinal and aromatic plants contain chemical compounds, with antioxidant and therapeutic activities. Among these various kinds of natural substances, phenolic compounds including flavonoids, are receiving particular attention.

The genus Mentha L. (Lamiaceae) is widely distributed throughout the temperate regions of the world, and in Iran is represented by 6 species. Mentha species have been extensively used for treatment of various diseases as well as for application in cosmetic and food industries (5). They are well known worldwide for antioxidant, antimicrobial, and antiviral activities $(2,6)$. In Iranian Traditional Medicine, these plants have found application as tonic, digestive, carminative, antispasmodic, stomachic, anti-inflammatory and flavoring remedies (6). However, literature data on the antiparasitic activity of the genus Mentha is scarce, and we know little about the scolicidal activity of the genus against protoscolices of hydatid cysts. Thus, the aim of the present work was to determine the biological activities, namely antioxidant and scolicidal effects, of the most common Mentha species growing in Iran (M. spicata L., M. aquatica L., M. longifolia L., M. × piperita L. var. citrata) in order to find further applications in the pharmaceutical industries.

\section{Material and Methods}

Plant material

Aerial parts of four Mentha species including M. spicata, M. aquatica, M. longifolia, $M . \times$ piperita var. citrata were collected in Mazandaran province, Iran, in 2017, at three different seasonal stages (5 April, 5 June and 5 August, hereafter April, June and August, respectively). The botanical identification was performed by the first author (M.R.) and voucher specimens were deposited at the Herbarium of the Department of Biology, Mazandaran University, Babolsar, Iran (IR-2017/345-348).

\section{Preparation of extracts}

Aerial parts of each specimen (100 g) were powdered to a homogenous particle size, and macerated in either ethanol or methanol at room temperature for 48 hours. After filtration, the crude extract was evaporated to dryness under reduced pressure, and then dissolved in $80 \%$ methanol to the final dilution as required, except for determination of scolicidal activity, in which the dried extract was dissolved in physiological serum.

Total phenolic, flavonoid and flavonol contents The concentrations of phenolic compounds in the extracts were determined according to the method published by Kim et al, with slight modifications, and results were expressed as mg gallic acid equivalents per gram dry weight of sample (GAE/g dw) (7). The total flavonoid and flavonol contents in the extracts (expressed in milligram quercetin per $\mathrm{g}$ of plant material $(\mathrm{mg} \mathrm{Q} / \mathrm{g} \mathrm{dw})$ were determined according to Moreno et al and Ložienè et al methods, respectively $(8,9)$.

DPPH radical scavenging and reducing power assays The antioxidant activities of methanol and ethanol extracts were determined by the DPPH free radical scavenging assay method as previously described (10). The ability of the extracts to reduce ferric ions $\left(\mathrm{Fe}^{+3}\right)$ was determined according to the method published by Yen and Chen $(11,12)$.

\section{Scolicidal activity}

Hydatid cysts protoscolices were collected from the livers of infected sheep in Northern Iran, at Mazandaran, Amol. The viability of protoscolices was assessed by $0.1 \%$ eosin staining under light microscopy. To determine the scolicidal activity of methanol and ethanol extracts against protoscolices of hydatid cysts, five dilutions $(20,40,60,90$ and $120 \mathrm{mg} / \mathrm{mL}$ ) of extracts were used for $1,3,5,10,20$ and 30 minutes. $0.5 \mathrm{~mL}$ of the protoscolices solution was placed in test tubes and $0.5 \mathrm{~mL}$ of various concentrations of extracts was added to each test tube. Contents of the tubes were gently mixed and incubated at $37^{\circ} \mathrm{C}$ for $1,3,5$, 10, 20 and $30 \mathrm{~min}$. The upper parts of the solution were removed with a pipette and $1 \mathrm{~mL}$ of $0.1 \%$ eosin stain was added to protoscolices. The protoscolicidal activity of each solution was determined by counting of 250 protoscolices (13). In control, Mentha extracts were excluded from the medium containing protoscolices. Sterile control was a medium without the parasite. In positive control, the standard drug albendazole (Pourateb, Iran) was used (50 $\mu \mathrm{g} / \mathrm{mL})$ against protoscolices.

\section{Statistical analysis}

All experiments were carried out in triplicate, and the data were analyzed using analysis of variance (ANOVA) and significant differences among means at $(P<0.05)$ were determined by Duncan's test using SPSS 16 (SPSS Inc., USA) software.

\section{Results}

Extract yields

The extract yields of the four Mentha species were obtained by using methanol and ethanol evaluated at three harvest times (Table 1). Variations in the yields of 
Table 1. Methanol/Ethanol extract yields of four Mentha species over growing season

\begin{tabular}{|c|c|c|c|c|c|c|}
\hline \multirow{2}{*}{ Taxa } & \multicolumn{2}{|c|}{ April } & \multicolumn{2}{|c|}{ June } & \multicolumn{2}{|c|}{ August } \\
\hline & Methanol & Ethanol & Methanol & Ethanol & Methanol & Ethanol \\
\hline M. spicata & 12 & 8.5 & 18.8 & 12.9 & 23.3 & 17.2 \\
\hline M. aquatica & 9.2 & 8.8 & 12.9 & 10.5 & 19.5 & 13.5 \\
\hline M. longifolia & 18.9 & 11.5 & 19.5 & 12 & 20.75 & 14.5 \\
\hline M. $\times$ piperita var. citrata & 13.6 & 9 & 15.2 & 9.8 & 17.4 & 11 \\
\hline
\end{tabular}

extracts with respect to the species, the solvent type and harvest times were significant $(P<0.05)$. Regardless of the species and harvest dates, the extract yields obtained by both methanol and ethanol more or less increased over the growing season. However, comparing extract yields obtained by using both solvents in all the species examined revealed that the methanolic extracts gave higher yields than ethanolic ones. This was ranged 12-23.3, 9.2-19.5, 18.9-20.75 and 13.6-17.4 in M. spicata, M. aquatica, $M$. longifolia and $M . \times$ piperita var. citrata, respectively. The methanol extract yield in all of the examined taxa showed a constant increase through the growing season, reaching the maximum value in August (Table 2).

Phenolic compounds

We evaluated the total phenolic, flavonoid and flavonol contents of the examined taxa. Sample content of phenolic compounds (expressed in mg GAE/g dw) in methanol and ethanol extracts of four Mentha species are summarized in Table 3. Our study showed that the solvent type had a significant effect on the recovery of phenolics. According to Table 3, methanol was the solvent with higher efficiency for recovering total phenolics. The only exception was the values measured in June for $M . \times$ piperita var. citrata using ethanol, which was second in rank only to methanol in June for the same taxon. Moreover, the higher concentration of phenolic content for both solvents was recorded in June. Generally, the four Mentha species showed high TPC ranging from 61.2 (M. longifolia) to 191.6 (M. × piperita var. citrata) $\mathrm{mg} \mathrm{GAE} / \mathrm{g}$, showing a difference up to 3-fold. The amount of TPC varied with respect to both species and the solvent used; the highest TPC was detected in $M$. $\times$ piperita var. citrata collected in June using both solvents (191.6 and $159.1 \mathrm{mg} \mathrm{GAE} / \mathrm{g}$, respectively), and the lowest

Table 2. Total phenolics of four Mentha species, as affected by harvest date and solvent type

\begin{tabular}{|c|c|c|c|c|c|c|}
\hline \multirow{3}{*}{ Species } & \multicolumn{6}{|c|}{ Total phenolic (mg GAE/g dw) } \\
\hline & \multicolumn{3}{|c|}{ Methanol } & \multicolumn{3}{|c|}{ Ethanol } \\
\hline & April & June & August & April & June & August \\
\hline M. spicata & $91.8^{i}$ & $122.2^{\mathrm{c}}$ & $87.1^{\prime}$ & $74.5^{n}$ & $87.2^{1}$ & $67.6^{p}$ \\
\hline M. aquatica & $111.7^{\mathrm{e}}$ & $92.3^{i}$ & $114.7^{\mathrm{d}}$ & $71.6^{\circ}$ & $68.1^{p}$ & $81.3^{\mathrm{m}}$ \\
\hline M. longifolia & $92^{i}$ & $98.4^{\mathrm{g}}$ & $87.9^{k}$ & $63^{9}$ & $67.6^{p}$ & $61.2^{r}$ \\
\hline M. $\times$ piperita var. citrata & $111.4^{\mathrm{e}}$ & $191.6^{\mathrm{a}}$ & $109.8^{f}$ & $89.8^{j}$ & $159.1^{\mathrm{b}}$ & $97.2^{\mathrm{h}}$ \\
\hline
\end{tabular}

Note: Means with the same letter are not significantly different $(P<0.05)$.

Table 3. Total flavonoid and flavonol contents of four Mentha species, as affected by harvest season and solvent type

\begin{tabular}{|c|c|c|c|c|c|c|}
\hline \multirow{2}{*}{ Taxa } & \multicolumn{3}{|c|}{ Methanol } & \multicolumn{3}{|c|}{ Ethanol } \\
\hline & April & June & August & April & June & August \\
\hline \multicolumn{7}{|c|}{ Total flavonoid content (mg Q/g dw) } \\
\hline M. spicata & $29^{m}$ & $34.6^{\mathrm{h}}$ & $37.4^{f}$ & $23.2^{q}$ & $31.1^{\mathrm{k}}$ & $33.4^{j}$ \\
\hline M. aquatica & $38.9^{d}$ & $38.1^{\mathrm{e}}$ & $51.6^{\mathrm{b}}$ & $32.4^{j}$ & $26.9^{\circ}$ & $37.1^{f}$ \\
\hline M. longifolia & $24.2^{p}$ & $28.1^{\mathrm{n}}$ & $30.1^{\prime}$ & $17.8^{\mathrm{u}}$ & $18.6^{t}$ & $20.6^{s}$ \\
\hline M. $\times$ piperita var. citrata & $36.3^{\mathrm{g}}$ & $46.12^{\mathrm{c}}$ & $57^{a}$ & $21.8^{r}$ & $36.1^{\mathrm{g}}$ & $37.7^{\text {ef }}$ \\
\hline \multicolumn{7}{|c|}{ Total flavonol content (mg Q/g dw) } \\
\hline M. spicata & $9.1^{\mathrm{i}}$ & $11.1^{\mathrm{f}}$ & $12.1^{\mathrm{d}}$ & $6.7^{\mathrm{m}}$ & $8.1^{k}$ & $9.6^{\mathrm{h}}$ \\
\hline M. aquatica & $11.7^{\text {de }}$ & $11.8^{\text {de }}$ & $12.9^{c}$ & $9.1^{\mathrm{i}}$ & $10.1^{\mathrm{g}}$ & $11.5^{\mathrm{ef}}$ \\
\hline M. longifolia & $7.4^{1}$ & $8.6^{\mathrm{j}}$ & $10.2^{\mathrm{g}}$ & $6.5^{\mathrm{m}}$ & $8.1^{\mathrm{k}}$ & $8.3^{\mathrm{jk}}$ \\
\hline M. $\times$ piperita var. citrata & $11.1^{f}$ & $14.2^{b}$ & $15.3^{\mathrm{a}}$ & $8.4^{\mathrm{jk}}$ & $11.1^{f}$ & $12.9^{c}$ \\
\hline
\end{tabular}

Note: Means with the same letter are not significantly different $(P<0.05)$. 
in M. longifolia collected in August and April using ethanol (61.2 and $63 \mathrm{mg} \mathrm{GAE} / \mathrm{g}$, respectively) (Table 3).

The TFvC of the crude extracts from Mentha species are summarized in Table 4. The maximum content was recorded in the methanol extracts. The highest level of TFvC was recorded in $M . \times$ piperita var. citrata (15.3 and $14.2 \mathrm{mg} \mathrm{Q} / \mathrm{g} \mathrm{dw}$ in August and June, respectively), followed by $M$. aquatica (12.9 mg Q/g dw in August), while the minimum levels were found in M. longifolia methanol extract (7.4 mg Q/g dw in April) and M. spicata ethanol extract (8.1 $\mathrm{mg} \mathrm{Q} / \mathrm{g} \mathrm{dw}$ in June).

\section{Antioxidant activity}

Two antioxidant assays i.e. free radical scavenging activity (DPPH assay) and reducing power assay were used for determining the antioxidant capacity of four Mentha species extracts.

Free radical scavenging activity (DPPH assay)

DPPH radical scavenging activity of Mentha species extracts are shown in Table 5. The addition of different dilutions of Mentha extracts to the DPPH solution induced a rapid decrease in the optical density at $517 \mathrm{~nm}$. In all of the tested materials, increase in the concentration of the solvent ranging from 10 to $100 \mu \mathrm{g} / \mathrm{mL}$, resulted in the significantly better free radical scavenging activity over 2-fold. Furthermore, all extracts obtained by using methanol gave stronger radical scavenging capacity than those prepared with ethanol. The extracts obtained by methanol yielded DPPH radical scavenging activity ranging from 3.3\% (August, $10 \mu \mathrm{g} / \mathrm{mL}$, M. spicata) to 89.6\% (June, $100 \mu \mathrm{g} / \mathrm{mL}, M . \times$ piperita var. citrata). This was between $1.8 \%$ (August, $10 \mu \mathrm{g} / \mathrm{mL}$, M. spicata) and $83.2 \%$ (June, $100 \mu \mathrm{g} / \mathrm{mL}, M . \times$ piperita var. citrata) for ethanol extracts.

Calculation of extract concentrations providing 50\% inhibition $\left(\mathrm{IC}_{50}\right)$ for both methanol and ethanol extract are also presented in Table 5. In methanolic Mentha extracts, the least $\mathrm{IC}_{50}$ value was recorded in $M . \times$ piperita var. citrata (June, $52.7 \mu \mathrm{g} / \mathrm{mL}$ ), while the extracts obtained from the August harvest of $M$. longifolia gave the highest value $(78.9 \mu \mathrm{g} / \mathrm{mL})$. The lowest and the highest $\mathrm{IC}_{50}$ values yielded by ethanolic Mentha extracts were recorded in $M$. $\times$ piperita var. citrata (June, $60.9 \mu \mathrm{g} / \mathrm{mL}$ ) and M. longifolia (April, $110.5 \mu \mathrm{g} / \mathrm{mL}$ ).

\section{Ferric reducing antioxidant power assay}

The reducing power of the extracts, which reflects their antioxidant activity, was determined using a $\mathrm{Fe}^{3+}$ to $\mathrm{Fe}^{2+}$ reduction assay. The reducing power of the alcoholic (methanol \& ethanol) extracts from four Mentha species was measured using three levels of concentration (100, 200 and $400 \mu \mathrm{g} / \mathrm{mL}$ ), and results are summarized in Table 6 as absorbance values (AV) at $700 \mathrm{~nm}$.

The highest reducing power was exhibited by methanol extracts at the concentration of $400 \mu \mathrm{g} / \mathrm{mL}$, and the ethanol at the concentration of $100 \mu \mathrm{g} / \mathrm{mL}$ showed the least activity. The reducing power of the methanol extracts yielded AVs between 0.189 in M. spicata (August, $100 \mu \mathrm{g} / \mathrm{mL}$ ) and 1.16 in $M . \times$ piperita var. citrata (June, $400 \mu \mathrm{g} / \mathrm{mL}$ ). AV was ranged between 0.04 in M. spicata and M. longifolia (5 April, $100 \mu \mathrm{g} / \mathrm{mL}$ ) and 1.13 in $M . \times$ piperita var. citrata (June, $400 \mu \mathrm{g} / \mathrm{mL}$ ) in the methanol extracts. In general, reducing power for all species, growth seasons and solvent types enhanced by nearly 2 -fold, as the concentration of the solvent was increased. In general, the methanol extracts of $M . \times$ piperita var. citrata at the concentration of $400 \mu \mathrm{g} / \mathrm{mL}$ gave the best reducing power.

Scolicidal activity

The scolicidal activity of methanol extracts from four Mentha species against protoscolices of hydatid cysts was

Table 4. Free-radical scavenging activity (DPPH assay) (\%) under different solvent type, solvent concentrations and Mentha species

\begin{tabular}{|c|c|c|c|c|c|c|c|c|c|}
\hline \multirow{3}{*}{ Taxa } & & \multicolumn{8}{|c|}{ Concentration $(\mu \mathrm{g} / \mathrm{mL})$} \\
\hline & & \multicolumn{4}{|c|}{ Methanol } & \multicolumn{4}{|c|}{ Ethanol } \\
\hline & & 10 & 40 & 100 & $\mathrm{IC}_{50}$ & 10 & 40 & 100 & $\mathrm{IC}_{50}$ \\
\hline \multirow{3}{*}{ M. spicata } & April & 9.7 & 31.9 & 71.8 & 68.3 & 8.7 & 28 & 63.3 & 78.2 \\
\hline & June & 7.9 & 33.7 & 80.6 & 62.7 & 7.5 & 28.9 & 77.1 & 65.9 \\
\hline & August & 3.3 & 24.8 & 58 & 86.4 & 1.8 & 22.5 & 56.7 & 88.7 \\
\hline \multirow{3}{*}{ M. aquatica } & April & 10.3 & 36.5 & 79.86 & 61.3 & 7 & 21.6 & 55.5 & 90.9 \\
\hline & June & 8.2 & 23.2 & 77.5 & 68.3 & 5.2 & 20.2 & 48.7 & 103.6 \\
\hline & August & 13.3 & 37.1 & 81.6 & 58.3 & 7 & 26 & 63.7 & 79.4 \\
\hline \multirow{3}{*}{ M. longifolia } & April & 10.9 & 26.6 & 65.7 & 76.4 & 5.3 & 15.2 & 46.4 & 110.5 \\
\hline & June & 12.6 & 38 & 77.2 & 61.6 & 6 & 29.9 & 69.7 & 72.3 \\
\hline & August & 9 & 22.5 & 64.7 & 78.9 & 6 & 20.9 & 53.3 & 94.8 \\
\hline \multirow{3}{*}{ M. $\times$ piperita var. citrata } & April & 10.7 & 35.7 & 76.2 & 62.9 & 8.1 & 29.1 & 73.6 & 68.6 \\
\hline & June & 16.9 & 37.9 & 89.6 & 52.7 & 13.1 & 30.2 & 83.2 & 60.9 \\
\hline & August & 13.9 & 37.6 & 81.7 & 58.1 & 7 & 29.4 & 75.7 & 67.5 \\
\hline
\end{tabular}


Table 5. Reducing power (absorbance at $700 \mathrm{~nm}$ ) of different extracts from four Mentha species

\begin{tabular}{|c|c|c|c|c|c|c|c|}
\hline \multirow{3}{*}{ Taxa } & & \multicolumn{6}{|c|}{ Concentration $(\mu \mathrm{g} / \mathrm{mL})$} \\
\hline & & \multicolumn{3}{|c|}{ Methanol } & \multicolumn{3}{|c|}{ Ethanol } \\
\hline & & 100 & 200 & 400 & 100 & 200 & 400 \\
\hline \multirow{3}{*}{ M. spicata } & April & 0.205 & 0.284 & 0.549 & 0.04 & 0.11 & 0.259 \\
\hline & June & 0.255 & 0.442 & 0.621 & 0.145 & 0.385 & 0.711 \\
\hline & August & 0.189 & 0.224 & 0.494 & 0.1 & 0.269 & 0.599 \\
\hline \multirow{3}{*}{ M. aquatica } & April & 0.242 & 0.353 & 0.612 & 0.11 & 0.237 & 0.499 \\
\hline & June & 0.247 & 0.365 & 0.623 & 0.06 & 0.194 & 0.497 \\
\hline & August & 0.313 & 0.451 & 0.725 & 0.11 & 0.243 & 0.551 \\
\hline \multirow{3}{*}{ M. longifolia } & April & 0.199 & 0.244 & 0.544 & 0.04 & 0.128 & 0.388 \\
\hline & June & 0.281 & 0.4 & 0.703 & 0.11 & 0.266 & 0.575 \\
\hline & August & 0.286 & 0.328 & 0.565 & 0.06 & 0.193 & 0.529 \\
\hline \multirow{3}{*}{ M. $\times$ piperita var. citrata } & April & 0.305 & 0.386 & 0.782 & 0.125 & 0.288 & 0.688 \\
\hline & June & 0.404 & 0.623 & 1.16 & 0.234 & 0.583 & 1.13 \\
\hline & August & 0.343 & 0.394 & 0.791 & 0.188 & 0.287 & 0.645 \\
\hline
\end{tabular}

also examined. The reference synthetic drug, Albendazole, was also applied $(50 \mu \mathrm{g} / \mathrm{mL})$ as positive control, and the parasiticidal activity of the plant extracts was compared with that of this drug. Our results demonstrated that 50 $\mu \mathrm{g} / \mathrm{mL}$ albendazole killed $97.3 \%$ and $100 \%$ of the scolices in 10 and 20 minutes, respectively. Table 6 and Figure 1 show the scolicidal activity of the alcoholic extracts from Mentha species prepared in various dilutions (15-200 $\mathrm{mg} / \mathrm{mL}$ ) and applied at four different (1-30 minutes) exposure times against protoscolices of E. granulosus.
The viability of protoscolices was significantly affected in the experiment. In all of the tested samples, the scolicidal activity showed a constant increase, as the concentration of the extract intensified; with respect to exposure time and concentration of the extract, the lowest/highest activities were observed at concentrations 15 and 200 $\mathrm{mg} / \mathrm{mL}$ of the methanol extracts after 1 and 30 minutes of application, respectively. Our results also indicated that with the exception of 1 minute of exposure in M. aquatica, M. longifolia and $M . \times$ piperita var. citrata, in all of the

Table 6. Scolicidal activity (\%) of the metanolic extracts from four Mentha species against protoscolices of hydatid cysts

\begin{tabular}{|c|c|c|c|c|c|c|c|}
\hline \multirow{2}{*}{ Taxa } & \multirow{2}{*}{ Time (min) } & \multicolumn{6}{|c|}{ Concentration $(\mathrm{mg} / \mathrm{mL})$} \\
\hline & & 15 & 45 & 70 & 100 & 150 & 200 \\
\hline \multirow{5}{*}{ M. spicata } & 1 & 7.32 & 9.15 & 14.57 & 32.56 & 34.64 & 92.08 \\
\hline & 5 & 9.62 & 9.49 & 25.31 & 34.3 & 52.62 & 93.3 \\
\hline & 10 & 12.03 & 12.3 & 30.65 & 40.52 & 58.83 & 95.55 \\
\hline & 20 & 13.37 & 13.79 & 32.64 & 45.01 & 61.52 & 98.3 \\
\hline & 30 & 14.03 & 15.81 & 34.54 & 53.74 & 80.1 & 98.98 \\
\hline \multirow{5}{*}{ M. aquatica } & 1 & 14.91 & 23.8 & 24.32 & 26.28 & 54.77 & 84.97 \\
\hline & 5 & 15.35 & 24.75 & 25.29 & 26.55 & 55.97 & 96.56 \\
\hline & 10 & 16.01 & 25.76 & 26.3 & 26.9 & 58.25 & 99.25 \\
\hline & 20 & 16.69 & 26.87 & 27.4 & 27.42 & 63.1 & 99.31 \\
\hline & 30 & 17.4 & 27.94 & 28.6 & 28.77 & 64.72 & 99.54 \\
\hline \multirow{5}{*}{ M. longifolia } & 1 & 11.04 & 11.55 & 20.93 & 25.38 & 48.52 & 88.2 \\
\hline & 5 & 11.11 & 11.6 & 23.37 & 26.63 & 51.03 & 92.73 \\
\hline & 10 & 11.15 & 11.62 & 24.85 & 38.48 & 57.74 & 92.85 \\
\hline & 20 & 11.24 & 11.71 & 25.42 & 40.35 & 58.45 & 97.48 \\
\hline & 30 & 11.35 & 11.76 & 25.69 & 41.08 & 60.8 & 99.11 \\
\hline \multirow{5}{*}{ M. $\times$ piperita var. citrata } & 1 & 9.46 & 11.33 & 14.25 & 25.93 & 44.41 & 84.14 \\
\hline & 5 & 11.92 & 11.98 & 14.69 & 26.58 & 46.94 & 97.2 \\
\hline & 10 & 25.31 & 26.61 & 26.78 & 43.47 & 48.68 & 97.7 \\
\hline & 20 & 27.11 & 40.05 & 47.39 & 48.17 & 72.48 & 97.7 \\
\hline & 30 & 28.72 & 52.5 & 60.4 & 62.88 & 93.22 & 98.9 \\
\hline
\end{tabular}




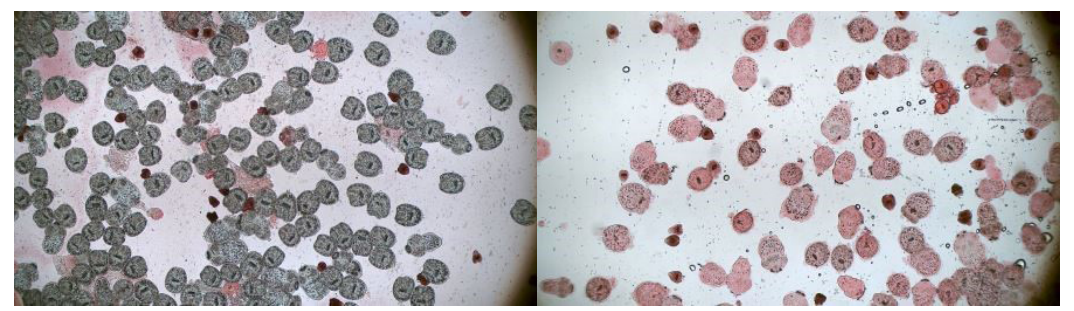

Figure 1. Scolicidal activity of Mentha aquatica methanolic extract against protoscolices of hydatid cysts at concentration of $200 \mathrm{mg} / \mathrm{mL}$; intact and viable protoscolices (Left), ex-posed protoscolices (Right).

taxa, the methanol extracts at concentration $200 \mathrm{mg} / \mathrm{mL}$ showed the most potent (over 90\%) scolicidal activity. The highest activity was observed with $200 \mathrm{mg} / \mathrm{mL}$ of methanol extract from M. aquatica after 30 (99.54\%), 20 (99.31\%) and $10(99.25 \%)$ minutes of application, followed by $98.98 \%$ and $98.3 \%$ of inhibition for $M$. spicata extract after 30 and 20 minutes of application, respectively. At this concentration, the lowest values were recorded in $M$. $\times$ piperita var. citrata (84.14\%), M. longifolia (88.2\%) and M. aquatica (84.97\%) after 1 minute of application. For all of the taxa and exposure times, the mortality given by extracts at concentrations below $200 \mathrm{mg} / \mathrm{mL}$ remained below $90 \%$, except for the extract of $M . \times$ piperita var. citrata, which yielded $93.22 \%$ of mortality in 30 minutes treatment and at concentration of $150 \mathrm{mg} / \mathrm{mL}$.

\section{Discussion}

Overall, our findings indicated that the extraction could vary in quantity and quality according to climate as well as age and vegetative cycle (14). Medicinal plants synthesize and accumulate phenolics in response to environmental stress and other corresponding factors $(15,16)$. In relation to our study, synthesis of phenolic derivatives e.g. flavonoids is reported to be upregulated when plants are overexposed to light (17). Moreover, we concluded that the variation in the recovery yields of crude extracts prepared from Mentha species could be explained by the difference in the solubility of certain compounds in the solvents employed. Bioactive compounds from plants belong to various chemical groups (e.g. terpenes, phenolics, alkaloids, glycosides, etc), and therefore, exhibit different solubility in certain solvents. Methanol in most cases is used in the extraction of polar bioactive components from plants. Numerous non-polar components are also dissolved in methanol and can be extracted, except for instances where only non-polar compounds are required to be extracted, and then it will surely require the use of solvents that are strictly non-polar. Therefore, methanol is commonly used for extraction of a wide range of bioactive compounds, as it is relatively inexpensive, easily evaporated and dissolves a wide range of compounds from polar to non-polar. In general, our results suggested that absolute methanol could be the solvent of choice for yielding high levels of extractable compounds. These findings were in line with previous studies on e.g. Limnophila aromatica
(Lam.) Merr. (13) and Phoenix dactylifera L. (18).

It has been widely proposed to prepare herbal medicines as mixtures (extracts) rather than isolates, as their activity is potentiated when delivered in mixtures (19). Phenolic compounds are a vital part of the human diet, and are of considerable interest due to their biological and physiological activities (e.g. antioxidant, anticarcinogenic, antimutagenic and anti-inflammatory effects) (20). They can basically be categorized into several classes, of which flavonoids are bioactive substances occurring widely in food and industrial plants. Flavonols are the most prevalent group of flavonoids in plants and occur in many fruits, vegetables and medicinal plants (21). The extraction of polyphenols in plants can be difficult, as these compounds are extremely different in structure; they may occur in plant tissues combined with sugars, proteins or they may give rise to polymerized derivatives showing various levels of solubility. Their chemical structure and interactions with other food components, which are not fully known, are a very important information to select the appropriate solvent and extraction conditions. Therefore, the recovery of polyphenols from plant materials is influenced by their solubility in the solvent, polarity of the solvent, degree of polymerization of phenols, interaction with other plant constituents and formation of insoluble complexes. According to the results obtained by a number of researchers worldwide (22-25), we found out that application of the more polar solvent, i.e. methanol, led to a higher recovery rate of phenolic compounds in Mentha species. Along with such matters, the content of phenolic compounds in Mentha species was obviously under the influence of both genetic makeup (genotype) and developmental stage (harvest date) of plants. Scientific evidence reveals that biosynthesis of SMs is not a random process, but rather highly ordered with respect to plant development (26). Many researchers worldwide have evaluated the effect of physiological development stage on the productivity of medicinal plants. To name a few, Kiani et al reported that the distribution of SMs might change during plant development, in relation to climatic conditions of the plant's habitat, which stimulate the biosynthesis of active substances (27). Besides, Medini et al argued that the quantity and the biological activity of phenolic compounds in Limonium delicatulum (Girard) Kuntze were significantly affected by physiological 
stages at which the plants were harvested (22). Moreover, Mikami-Konishide et al reported that the antioxidant capacity and phenol content of six crops cultivated in Japan were strongly affected by the growing season (28).

The antioxidant capacities of the plant extracts cannot be fully described with only one method, but it is necessary to perform more than one type of antioxidant capacity measurement to consider the occurrence of various mechanisms of antioxidant activity (29). The most commonly used methods for the determination of antioxidant activity are DPPH radical scavenging and ferric reducing power assays (30). Results of our study revealed that either methanol or ethanol extracts of Mentha species had high DPPH activity and ferric reducing power. Generally, the antioxidant capacities of the plant extracts largely depend on the composition of the extracts and conditions of the test system. Therefore, all the aforementioned factors (e.g. agroclimatic conditions, laboratory conditions etc) influencing the recovery of plant extracts, would accordingly affect the antioxidant capacity of plants. Today, we know that additive and synergistic effects of phytochemicals in plants are responsible for their potent antioxidant activity, and that the benefit of a diet rich in fruit and vegetables is attributed to the complex mixture of phytochemicals present in the body of the plants, not a single compound (31). A large number of medicinal plants contain chemicals with antioxidant activity, among which phenolics and their derivatives are receiving particular attention (32). The largest and best studied natural phenolics in plants are flavonoids, which include numerous compounds e.g. anthocyanidins, flavonols, flavones, flavanones, flavan3-ols and isoflavonoids (33). The antioxidant activity of phenolic compounds is due to their ability to scavenge free radicals, donate hydrogen atoms or electron, or chelate metal cations (34). For example, the phenolic moiety in flavonoids can accept an electron to form relatively stable phenoxyl radicals, thereby disrupting chain oxidation reactions in cellular components (33). This might also be associated with the free radical scavenging activity of a variety of enzymes namely superoxide dismutase, catalase, peroxidase, etc as well as the presence of carotenoids, tocopherol and ascorbic acid. The synergistic effects of polyphenols, flavonoids, phenolic acids etc should also be taken into account.

There is a growing interest of industry to replace synthetic chemicals by natural products with bioactive properties of plant origin (35). Despite increasing interest in phytochemical research, a few attempts have been made to identify antiparasitic agents from medicinal plants. The potential of the mint family to disturb the viability of protoscolices has been investigated and some show significant activity. In relation to our study, for example, Mentha piperita, Mentha pulegium, Salvia officinalis, Satureja khuzestanica, Thymus vulgaris and Zataria multiflora, ethnobotanically known as anthelmintics, have been employed to combat Echinococcus granulosus (36). Two pure phenolic compounds menthol and thymol, the principal components of Mentha arvensis and Thymus vulgaris essential oils (EOs), respectively, were tested by Yones et al and showed excellent scolicidal activity (37). The major products of Mentha pulegium and Mentha piperita EOs, which were successfully used by Maggiore et al against Echinococcus granulosus were piperitone oxide and isomenthol, respectively (38). Elissondo et al used the phenolic compound thymol against the parasite and the same result was obtained (35). Likewise, Mahmoudvand et al reported that thymol and carvacrol, the main constituents of Zataria multiflora EO, were completely effective to kill protoscolices (39). As with abovementioned cases, the bioactivity of a given plant is mostly decided by either one or two of its main components. However, sometimes overall activity cannot be attributed to any of the major constituents, and additive or even synergistic effects in the presence of other compounds within a crude mixture modifies the activity to exert significant effect (40). There is evidence that crude plant extracts often have greater biological activity than isolated constituents at an equivalent dose. In traditional medicine whole plants or mixtures of plants are used rather than isolated compounds $(41,42)$. Many traditional systems of medicine have several crude formulations having promising effects on parasites, but unfortunately none of these formulations has been characterized till date. The literature data on the bioactivity of plants crude extract against protoscolices is scarce, and the present work is the first attempt made to investigate the scolicidal potential of crude extracts from taxa belonging to the genus Mentha. As it can be seen through the latter studies, in nearly all cases a phenolic substance is responsible for scolicidal activity of the tested plants. According to Verma et al, the loss in viability of the parasite is associated with a severe morphological alteration to the surface of the parasite leading to the disturbance in osmoregulatory system of protoscolices (43). Interestingly, a similar mode of action has been proposed for antimicrobial activity of phenolic compounds and the reference synthetic anthelmintic drugs praziquantel, benzimidazole and ivermectin (43). Taking all these into consideration, main mechanisms involved in scolicidal effects of phytochemicals remain poorly understood and elucidation of these mechanisms awaits further studies.

\section{Conclusion}

To sum up, the current study is an attempt to determine the antioxidant effects of the most common Mentha species growing in Iran, and to screen out a new source of natural drugs having promising effects against protoscolices. The initial results obtained are quite encouraging since crude extracts of Mentha exhibited potent antioxidant 
effect, and scolicidal activity close to some synthetic drugs. The tested taxa can be further investigated for chemical characterization leading to the understanding of mechanism of action. These results may have significant implications for the future development of anti-parasitic drugs derived from Mentha species.

\section{Acknowledgement}

We would like to thank Dr. Mostafa Govahi for his contribution by giving many helpful insights and suggestions.

\section{Authors' contributions}

$\mathrm{MR}$ and AN conceived and designed the analysis. MR and $\mathrm{MK}$ conducted the experiment and collected the data. AN performed the analysis. MK and MR interpreted the data and wrote the paper. All read and confirmed the final version of manuscript for publication

\section{Conflict of interest}

All authors confirm that there is no conflict of interest to disclose.

\section{Ethical considerations}

This study protocol was approved by the ethics committee of Amol University of Special Modern Technologies (Ethical code: ir.ausmt.rec.961110). The ethical issues (including plagiarism, misconduct, data fabrication, falsification, double publication or submission, redundancy) have been completely observed by the authors.

\section{Funding/Support}

This research has been supported by a research grant from the Amol University of Special Modern Technologies, Amol, Iran (35 - 96/20/3766).

\section{References}

1. Mimica-Dukić N, Bozin B, Soković M, Mihajlović B, Matavulj M. Antimicrobial and antioxidant activities of three Mentha species essential oils. Planta Med. 2003;69(5):413-9. doi: 10.1055/s-2003-39704.

2. Grul'ová D, Labun P, Šeršeň F, Šalamon I. Seasonal variation in DPPH scavenging activity of Mentha x piperita. Adv Environ Biol. 2012;6(4):1477-80.

3. Zibaei M, Sarlak A, Delfan B, Ezatpour B, Azargoon A. Scolicidal effects of Olea europaea and Satureja khuzestanica extracts on protoscolices of hydatid cysts. Korean J Parasitol. 2012;50(1):53-6. doi: 10.3347/kjp.2012.50.1.53.

4. Hammond JA, Fielding D, Bishop SC. Prospects for plant anthelmintics in tropical veterinary medicine. Vet Res Commun. 1997;21(3):213-28. doi: 10.1023/a:1005884429253.

5. Petrovska BB. Historical review of medicinal plants' usage. Pharmacogn Rev. 2012;6(11):1-5. doi: 10.4103/09737847.95849 .

6. Nickavar B, Alinaghi A, Kamalinejad M. Evaluation of the antioxidant properties of five Mentha species. Iran J Pharm
Res. 2010;7(3):203-9. doi: 10.22037/ijpr.2010.766.

7. Kim KT, Yoo KM, Lee JW, Eom SH, Hwang IK, Lee CY. Protective effect of steamed American ginseng (Panax quinquefolius L.) on V79-4 cells induced by oxidative stress. J Ethnopharmacol. 2007;111(3):443-50. doi: 10.1016/j. jep.2007.01.004.

8. Moreno MI, Isla MI, Sampietro AR, Vattuone MA. Comparison of the free radical-scavenging activity of propolis from several regions of Argentina. J Ethnopharmacol. 2000;71(1-2):109-14. doi: 10.1016/s03788741(99)00189-0.

9. Ložienė K, Venskutonis PR, Šipailienė A, Labokas J. Radical scavenging and antibacterial properties of the extracts from different Thymus pulegioides L. chemotypes. Food Chem. 2007;103(2):546-59. doi: 10.1016/j.foodchem.2006.08.027.

10. Singh HP, Mittal S, Kaur S, Batish DR, Kohli RK. Chemical composition and antioxidant activity of essential oil from residues of Artemisia scoparia. Food Chem. 2009;114(2):642-5. doi: 10.1016/j.foodchem.2008.09.101.

11. Yen GC, Chen HY. Antioxidant activity of various tea extracts in relation to their antimutagenicity. J Agric Food Chem. 1995;43(1):27-32

12. Do QD, Angkawijaya AE, Tran-Nguyen PL, Huynh LH, Soetaredjo FE, Ismadji S, et al. Effect of extraction solvent on total phenol content, total flavonoid content, and antioxidant activity of Limnophila aromatica. J Food Drug Anal. 2014;22(3):296-302. doi: 10.1016/j.jfda.2013.11.001.

13. Mahmoudvand $\mathrm{H}$, Mirbadie SR, Sadooghian S, Harandi MF, Jahanbakhsh S, Saedi Dezaki E. Chemical composition and scolicidal activity of Zataria multiflora Boiss essential oil. J Essent Oil Res. 2017;29(1):42-7. doi: 10.1080/10412905.2016.1201546.

14. Angioni A, Barra A, Coroneo V, Dessi S, Cabras P. Chemical composition, seasonal variability, and antifungal activity of Lavandula stoechas L. ssp. stoechas essential oils from stem/ leaves and flowers. J Agric Food Chem. 2006;54(12):436470. doi: 10.1021/jf0603329.

15. Ksouri R, Megdiche W, Debez A, Falleh H, Grignon C, Abdelly C. Salinity effects on polyphenol content and antioxidant activities in leaves of the halophyte Cakile maritima. Plant Physiol Biochem. 2007;45(3-4):244-9. doi: 10.1016/j.plaphy.2007.02.001.

16. Naczk M, Shahidi F. Extraction and analysis of phenolics in food. J Chromatogr A. 2004;1054(1-2):95-111.

17. Pavarini DP, Pavarini SP, Niehues M, Lopes NP. Exogenous influences on plant secondary metabolite levels. Anim Feed Sci Technol. 2012;176(1-4):5-16. doi: 10.1016/j. anifeedsci.2012.07.002

18. Kchaou W, Abbès F, Blecker C, Attia H, Besbes S. Effects of extraction solvents on phenolic contents and antioxidant activities of Tunisian date varieties (Phoenix dactylifera L.). Ind Crops Prod. 2013;45:262-9. doi: 10.1016/j. indcrop.2012.12.028.

19. Lila MA. Anthocyanins and human health: an in vitro investigative approach. J Biomed Biotechnol. 2004;2004(5):306-13. doi: 10.1155/s111072430440401x.

20. Huang WY, Cai YZ, Zhang Y. Natural phenolic compounds from medicinal herbs and dietary plants: potential use for cancer prevention. Nutr Cancer. 2010;62(1):1-20. doi: 10.1080/01635580903191585. 
21. Esselen M, Barth SW. Food-borne topoisomerase inhibitors: risk or benefit. In: Fishbein JC, Heilman JM, eds. Advances in Molecular Toxicology. Elsevier; 2014. p. 123-71. doi: 10.1016/B978-0-444-63406-1.00004-0.

22. Medini F, Fellah H, Ksouri R, Abdelly C. Total phenolic, flavonoid and tannin contents and antioxidant and antimicrobial activities of organic extracts of shoots of the plant Limonium delicatulum. J Taibah Univ Sci. 2014;8(3):216-24. doi: 10.1016/j.jtusci.2014.01.003.

23. Sengul M, Yildiz H, Gungor N, Cetin B, Eser Z, Ercisli S. Total phenolic content, antioxidant and antimicrobial activities of some medicinal plants. Pak J Pharm Sci. 2009;22(1):102-6.

24. Djeridane A, Yousfi M, Nadjemi B, Boutassouna D, Stocker P, Vidal N. Antioxidant activity of some Algerian medicinal plants extracts containing phenolic compounds. Food Chem. 2006;97(4):654-60. doi: 10.1016/j. foodchem.2005.04.028.

25. Goli AH, Barzegar M, Sahari MA. Antioxidant activity and total phenolic compounds of pistachio (Pistachia vera) hull extracts. Food Chem. 2005;92(3):521-5. doi: 10.1016/j. foodchem.2004.08.020.

26. Ncube B, Finnie JF, Van Staden J. Quality from the field: the impact of environmental factors as quality determinants in medicinal plants. S Afr J Bot. 2012;82:11-20. doi: 10.1016/j. sajb.2012.05.009.

27. Kiani M, Sefidkon F, Babaei A, Naghavi MR. Phytochemical profiling of medicinal isosteroidal alkaloids of Iranian Fritillaria spp. (Liliaceae). Ind Crops Prod. 2015;70:451-8. doi: $10.1016 /$ j.indcrop.2015.03.064.

28. Mikami-Konishide I, Murakami S, Nakanishi K, Takahashi Y, Yamaguchi M, Shioya T, et al. Antioxidant capacity and polyphenol content of extracts from crops cultivated in Japan, and the effect of cultivation environment. Food Sci Technol Res. 2013;19(1):69-79. doi: 10.3136/fstr.19.69.

29. Song FL, Gan RY, Zhang Y, Xiao Q, Kuang L, Li HB. Total phenolic contents and antioxidant capacities of selected Chinese medicinal plants. Int J Mol Sci. 2010;11(6):236272. doi: 10.3390/ijms11062362.

30. Iqbal T, Hussain AI, Chatha SA, Naqvi SA, Bokhari TH. Antioxidant activity and volatile and phenolic profiles of essential oil and different extracts of wild mint (Mentha longifolia) from the Pakistani Flora. J Anal Methods Chem. 2013;2013:536490. doi: 10.1155/2013/536490.

31. Liu RH. Health benefits of fruit and vegetables are from additive and synergistic combinations of phytochemicals. Am J Clin Nutr. 2003;78(3 Suppl):517S-20S. doi: 10.1093/ ajcn/78.3.517S.

32. Dorman HJ, Kosar M, Kahlos K, Holm Y, Hiltunen R. Antioxidant properties and composition of aqueous extracts from Mentha species, hybrids, varieties, and cultivars. J Agric Food Chem. 2003;51(16):4563-9. doi: 10.1021/jf034108k.

33. Shamloo M, Babawale EA, Furtado A, Henry RJ, Eck $\mathrm{PK}$, Jones PJH. Effects of genotype and temperature on accumulation of plant secondary metabolites in Canadian and Australian wheat grown under controlled environments. Sci Rep. 2017;7(1):9133. doi: 10.1038/ s41598-017-09681-5.

34. Złotek U, Mikulska S, Nagajek M, Świeca M. The effect of different solvents and number of extraction steps on the polyphenol content and antioxidant capacity of basil leaves (Ocimum basilicum L.) extracts. Saudi J Biol Sci. 2016;23(5):628-33. doi: 10.1016/j.sjbs.2015.08.002.

35. Elissondo MC, Pensel PE, Denegri GM. Could thymol have effectiveness on scolices and germinal layer of hydatid cysts? Acta Trop. 2013;125(3):251-7. doi: 10.1016/j. actatropica.2012.12.007.

36. Gangwar M, Verma VC, Singh TD, Singh SK, Goel RK, Nath G. In-vitro scolicidal activity of Mallotus philippinensis (Lam.) Muell Arg. fruit glandular hair extract against hydatid cyst Echinococcus granulosus. Asian Pac J Trop Med. 2013;6(8):595-601. doi: 10.1016/s1995-7645(13)60103-0.

37. Yones DA, Taher GA, Ibraheim ZZ. In vitro effects of some herbs used in Egyptian traditional medicine on viability of protoscolices of hydatid cysts. Korean J Parasitol. 2011;49(3):255-63. doi: 10.3347/kjp.2011.49.3.255.

38. Maggiore MA, Albanese AA, Gende LB, Eguaras MJ, Denegri GM, Elissondo MC. Anthelmintic effect of Mentha spp. essential oils on Echinococcus granulosus protoscoleces and metacestodes. Parasitol Res. 2012;110(3):1103-12. doi: 10.1007/s00436-011-2595-x.

39. Mahmoudvand H, Asadi A, Harandi MF, Sharififar F, Jahanbakhsh S, Dezaki ES. In vitro lethal effects of various extracts of Nigella sativa seed on hydatid cyst protoscoleces. Iran J Basic Med Sci. 2014;17(12):1001-6.

40. Raut JS, Karuppayil SM. A status review on the medicinal properties of essential oils. Ind Crops Prod. 2014;62:250-64. doi: 10.1016/j.indcrop.2014.05.055.

41. Rasoanaivo P, Wright CW, Willcox ML, Gilbert B. Whole plant extracts versus single compounds for the treatment of malaria: synergy and positive interactions. Malar J. 2011;10 Suppl 1:S4. doi: 10.1186/1475-2875-10-s1-s4.

42. Nikpay A, Soltani M. In vitro anti-parasitic activities of Pulicaria dysenterica and Lycopus europaeus methanolic extracts against Trichomonas gallinae. J Herbmed Pharmacol. 2018;7(2):112-8. doi: 10.15171/jhp.2018.19.

43. Verma VC, Gangwar M, Nath G. Osmoregulatory and tegumental ultrastructural damages to protoscoleces of hydatid cysts Echinococcus granulosus induced by fungal endophytes. J Parasit Dis. 2014;38(4):432-9. doi: 10.1007/ s12639-013-0271-z. 